\title{
EDITORIAL
}

\section{Hematopoietic stem cell transplants for chronic myeloid leukemia in Europe - Impact of cost considerations}

Leukemia (2007) 21, 383-386. doi:10.1038/sj.leu.2404509

Hematopoietic stem cell transplantation (HSCT) offers a unique opportunity for long-term disease control to many patients with severe malignant or non-malignant, acquired or congenital disorders of the hematopoietic system or with chemosensitive and radiosensitive tumors. It has seen rapid expansion over the last decades and it is integrated into the treatment algorithm for many disease categories from diagnosis. ${ }^{1-4}$ Still, HSCT is a high cost procedure and can present a financial challenge for patients and health-care systems in any country..$^{5-7}$ The impact of the economic strength of individual countries on HSCT has been reported earlier in detail by the European Group for Blood and Marrow Transplantation (EBMT). ${ }^{8,9}$ It explained the differences in numbers of transplants between Eastern and Western European countries. Transplant rates, that is numbers of HSCT per number of inhabitants, were higher in countries with higher gross national income (GNI) per capita or higher health-care expenditures per capita.

Despite major economic changes, differences in transplant rates between Western and Eastern European countries still prevail, but a novel observation was made in most recent years. Chronic myeloid leukemia was the most frequent indication for an allogeneic HSCT worldwide up to $1999 .^{9}$ With the introduction of imatinib mesylate, ${ }^{10,11}$ a BCR/ABL-specific tyrosine kinase inhibitor, transplant rates for this disease dropped rapidly and continued to do so until 2004. ${ }^{12}$ This drop in transplant rates was not identical in all European countries. It could have been expected that the advent of a highly efficacious drug therapy would induce a similar drop in transplant rates in all countries. This appears not to be the case. We noticed a stable number of HSCT for chronic myeloid leukemia in Eastern European countries. ${ }^{13}$ Consequently, we were interested in investigating the potential mechanisms behind these discordant changes in transplant rates for chronic myeloid leukemia and looked at economic factors of the individual European countries in a retrospective analysis, which is based on the prospective annual activity survey of the European Group for Blood and Marrow Transplantation (EBMT) (http://www.EBMT.org). We believe that these findings have broader implications. They might herald a new principle for similar situations when the choice between ongoing expensive drug therapies in general or once in a lifetime procedure becomes a matter of concern.

Since 1990, all EBMT members and affiliated teams were requested on an annual basis to report their numbers of patients transplanted in the previous year by indication, stem cell source and donor type. ${ }^{14}$ Data were validated by the reporting team, which received a computer printout of the entered data, and by cross-checking with national registries. Onsite visits of selected teams were part of the quality control programme. The EBMT survey constitutes an integral part of a comprehensive quality assurance programme JACIE (Joint Accreditation Committee of the International Society for Cellular Therapy (ISCT) and EBMT (http://www.JACIE.org)). Transplant rates, that is the number of HSCTs per 10 million inhabitants, were computed by disease indication and donor type for each country and for each year from 1991 to 2004 as defined previously. ${ }^{8}$ Population data were obtained from the World Bank (http://www.worldbank.org). Transplant rates in this survey cannot make adjustments for patients who cross borders and receive their HSCT in another country.

A total of 612 teams in 38 European and five affiliated countries were contacted for the 2004 report, of which 592 reported their numbers. This corresponds to a $97 \%$ return rate of active teams in 2004 and includes 481 of the 494 active EBMT member teams. No major transplant team in Europe is missing from this list. Teams are listed in the online Appendix in alphabetical order according to country, city and EBMT centre code. We received information that in 2004 no blood or marrow transplantations were performed in the following European countries: Albania, Andorra, Armenia, Georgia, Liechtenstein, Malta, Moldavia, Monaco, San Marino and the Vatican.

Countries were categorized by their GNI per capita according to the World Bank definitions into high income (Austria, Belgium, Cyprus, Denmark, Finland, France, Germany, Greece, Ireland, Italy, Netherlands, Norway, Portugal, Slovenia, Spain, Sweden, Switzerland and United Kingdom), middle income (Croatia, Czech Republic, Estonia, Hungary, Latvia, Lithuania, Poland, Slovakia) and low income countries (Azerbaijan, Belarus, Bosnia and Herzegovina, Bulgaria, Macedonia, Romania, Russia, Serbia and Montenegro, Ukraine and Turkey). The latter category refers to the World Bank definition of 'lower middle income' (http://www.worldbank.org). Non-European countries that traditionally participate in the EBMT activity survey (Algeria, Iran, Israel, Saudi Arabia and Tunisia; see online appendix and Gratwohl et al. ${ }^{12}$ ) were not included in the analysis. Iceland and Luxemburg were excluded because of some missing data. Representatives in each country were asked to provide information on the costs or the respective charges for an HSCT from an human leukocyte antigen (HLA) identical sibling donor as well as for the costs of 1-year treatment with imatinib at a dose of $400 \mathrm{mg}$ per day. Transplant rates by indication for each country were calculated to establish the weighted (by population size of the countries) means of transplant rates and their 95\% confidence limits for each year, in total and by World Bank classification. Trends over the 15 years period were analyzed by regression analyses for each of the three classified groups.

Trends of transplant rates from 1992 to 2004 for acute and chronic myeloid leukemia, the two most frequent indications for an allogeneic $\mathrm{HSCT}^{12}$ are illustrated in Figure 1. There were a total of 529 allogeneic HSCTs for acute myeloid leukemia in 1991. The number of such transplants increased to a total of 2404 HSCTs in 2004. Transplant rates increased from 12 to 47 per 10 million inhabitants in the high income countries, from 0.3 to 22 in the middle income countries and remained below 3 transplants per 10 million inhabitants in the low income countries. This increase was close to linear throughout the whole observation period with a clear distinction in absolute numbers, transplant rates and slope of the curve between the three World Bank categories (Figure 1a) and with a clear 


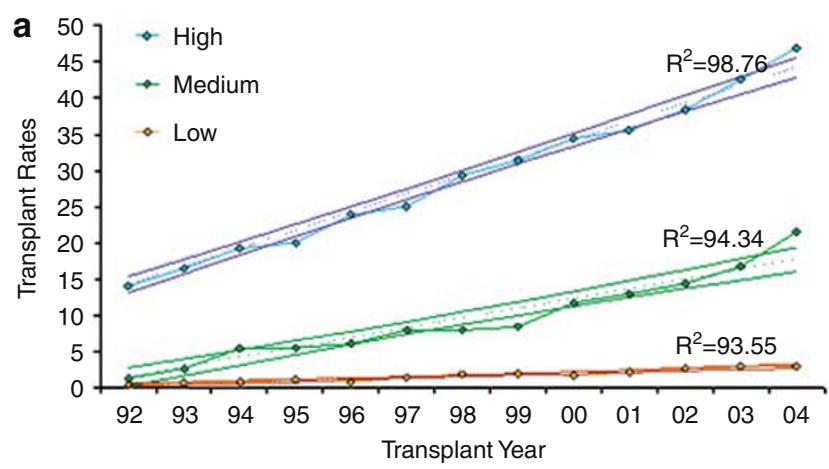

range 30000-32000 Euros) and middle income countries (median 32000 Euros; range 28 000-44000 Euros). Costs for an allogeneic HSCT from an HLA identical sibling ranged from 26515 to 180000 Euros with a median of 63450 Euros (mean 72173 Euros). Costs for a transplant ranged between 60000 and 180000 Euros (median 80000 Euros) in high income countries and between 27000 and 96000 Euros in middle income countries (median 52000 Euros). No reliable information could be obtained from low income countries.

Costs for a transplant have to be regarded with caution. They cannot be compared as directly as the costs for drug treatment. They reflect charges to patients in some, allocations to the hospital budget per transplant in other countries. They cover immediate pretransplant costs only in some, periods up to 3 months in other countries. Still, they give an estimate that the ratio between 1-year drug therapy and allogeneic HSCT varies from 0.9 to 5.9 with a median of 2.0 (mean 2.3).

These data confirm that HSCT rates in Europe are strongly influenced by the economic status of the individual countries. Countries with higher GNI per capita perform more transplantations than countries with lower income. The correlation is clear albeit loose. Transplant rates follow distinct patterns when countries are categorized by the World Bank category of high-, middle- or low income. GNI per capita has an impact on absolute numbers, on transplant rates and on the dynamics of increase over time. This comes as no surprise. It confirms and extends previous observations. $1,7,8,13$ However, the data show an additional and novel finding. Transplant rates for chronic myeloid leukemia followed the same pattern as for acute myeloid leukemia until 1999. Then, transplant rates dropped for chronic myeloid leukemia in high income countries but they remained stable in middle income countries. During most recent years, they remained within comparable boundaries for the two categories of high and middle income countries. These findings warrant an explanation.

The introduction of imatinib mesylate has changed attitudes towards HSCT and treatment algorithms have changed. In 1999, the general recommendation was to proceed whenever possible with an allogeneic HSCT if a HLA identical donor was available for a patient with chronic myeloid leukemia. ${ }^{15,16}$ This changed with the introduction of imatinib and the debate has been ongoing during the recent years. ${ }^{17,18}$ Current recommendations consider imatinib as the first choice. Allogeneic HSCT is reserved for patients with insufficient response to imatinib, with imatinib failure, or to the rare young patient with initial high risk disease and low risk donor. ${ }^{19}$

When imatinib appeared to replace the high cost procedure HSCT, an even greater drop in transplant rates could have been expected in economically less advantaged countries. ${ }^{7}$ This was not the case. The present data cannot give a definitive answer but it can provide some clues. Costs for a HSCT vary substantially between European countries. Main cost factors in HSCT are hospital room costs, drug expenditures and salaries for physicians and nursing staff. ${ }^{13,18,20-22}$ Hospital costs and salaries vary more markedly between countries and are primarily influenced by the general income of the respective countries. This is not the case for new drugs as illustrated by this analysis, drug costs for imatinib are the same throughout Europe. If anything, they appear higher in middle income countries. There is no standardized databank yet concerning costs for transplants in Europe and the data provided for this analysis have to be regarded with caution. Procedures for reimbursement vary markedly from country to country within Europe. Transplants are paid for by lump sums in some countries, they are based on detailed accounting in others. Charges might cover 
immediate transplant periods only in some or full time span up to day 100 in other countries. Still, the data give a clear insight. Costs for a transplant might be as low as 1-year drug treatment with imatinib in some countries. It might correspond to 5 years of drug treatment in others. Cost comparisons with imatinib have shown favorable results in the US. ${ }^{23,24}$ These findings appear not to apply in all countries.

Treatment with imatinib is currently considered as initial standard treatment for the majority of patients with early chronic myeloid leukemia. ${ }^{19}$ All information available so far suggests that treatment with imatinib might be required throughout life. Hence, expenses for drug treatment will continue throughout life. In contrast, for the majority of patients with an allogeneic HSCT, drug treatment can be withheld after a certain period of time. ${ }^{25}$ Any cost considerations therefore will need to reflect lifetime costs, not only initial costs of a procedure. In view of the high price of drug costs for 1-year treatment, allogeneic HSCT might become an attractive and relatively cost effective procedure. The data from this activity survey of the EBMT reflect that such considerations apparently already take place and that countries with GNIs in the World Bank category of middle income have adapted more rapidly to such considerations. Such thoughts have been expressed recently by the SouthAmerican and Mexican Blood and Marrow Transplant Group ${ }^{20}$ and at meetings in Eastern Europe. ${ }^{13}$ As shown by the data, cost considerations between two possible procedures are still irrelevant in low income countries where costs of either procedure are too high for the population at large and where access to any high cost procedure such as HSCT remains as difficult as has been discussed already two decades ago for Eastern European countries. ${ }^{26}$

Admittedly, data on factors behind the medical decision to proceed or not to proceed with HSCT cannot be retrieved by the EBMT survey. The report is based on assumptions, which are supported by the findings of the HSCT trends for acute myeloid leukemia. In acute myeloid leukemia, transplant rates depend primarily on World Bank category. In addition, curves of the trends show no indication for a plateau and are not indicative for saturation. The interpretation is that teams perform as many transplants for acute myeloid leukemia as they can with their current infrastructure. Even in high income countries, not all patients can be served with the procedure.

This report holds information, which is most likely not limited to chronic myeloid leukemia. It points to a situation, which might confront the medical community in the near future as a general principle. Many novel-specific and targeted drugs are currently in early trials or are being developed, for chronic myeloid leukemia and other myeloproliferative disorders. ${ }^{27}$ They will be expensive and it is easy to anticipate that costs for imatinib follow-up products ${ }^{28,29}$ will be in a similar range as imatinib. Until such drugs can provide for a cure without need for lifelong drug treatment, a once in a lifetime procedure such as HSCT may become attractive despite its immediate higher costs. The dilemma of choice between an early invasive but curative procedure and lifelong drug treatment will continue to grow in other areas. With the recent improvements in management of HSCT and the reduction of early mortality, HSCT may even become the preferred treatment in countries with limited resources. It is highly likely that the medical community will be confronted with such decisions, even more so in situations where patients or their families will have to carry the burden of the costs by themselves.

The list of participating teams (Appendix) can be seen as supplementary material for online viewing at http://www. nature.com/leu.

\section{Acknowledgements}

The cooperation of all participating teams and their staff (listed in the Appendix), the EBMT secretariat ( $F$ McDonald, E McGrath, $S$ Notely), the European EBMT Data Office in Paris (V Chesnel, NC Gorin), the EBMT Registry Subcommittee (C Ruiz de Elvira), the French Registry SFGM (D Blaise, Z Chir), the Dutch Registry TYPHON (A Schattenberg, Av Biezen, M Sneets), the Austrian Registry ( $\mathrm{H}$ Greinix, B Lindner), the Italian Registry (M Vignetti, A Bacigalupo, R Oneto, B Bruno), the German Registry DRST (H Ottinger, C Müller, K Fuchs), the Swiss Registry (U Schanz, H Baldomero), the British Registry BSBMT (C Craddock, K Towlson, M Wilson), the Turkish Registry (G Gurman, M Arat, F Arpaci, M Ertem), the Czech Registry (K Benesova, M Trnkova, H Krecjova) and the Spanish Hematopoietic Transplantation Group GETH (E Carreras, A Cedillo) is greatly appreciated. We also thank S Stöckli for excellent secretarial assistance as well as L John for technical assistance with data management. The work was supported in part by the European Leukemia Net LSH-2002-2.2.0-3, by a grant from the Swiss National Research Foundation, 3200BO-106105/1, the Swiss Cancer League, the Regional Cancer League and the Horton Foundation. EBMT is supported by grants from the corporate members: Amgen Europe, Hoffmann-La Roche Ltd, Gilead Sciences, Miltenyi Biotec $\mathrm{GmbH}$, Schering Plough, ChugaiAventis, Fresenius Biotech $\mathrm{GmbH}$, Gambro BCT, Genzyme, Pfizer, Schering AG, Therakos, Zeneus Pharma Ltd, Pierre Fabre, GE Healthcare and AnorMED Inc. EBMT is supported by the corporate members as outlined in the acknowledgements. There are no personal conflicts of interest to declare. Authors Contributions: AG and AUI designed the study and prepared the paper. HB was responsible for the data collection, MG for reassembling the data and preparing it for the analysis and AS and KF performed the data analysis. All contributed to the final version of this paper.

A Gratwohl $^{1}$, H Baldomero ${ }^{1}$, A Schwendener ${ }^{2}, \mathrm{M} \mathrm{Gratwohl}^{1}$, A Urbano-Ispizua ${ }^{3}$ and K Frauendorfer ${ }^{2}$, For the Joint Accreditation Committee of the International Society for Cellular Therapy (ISCT) and the European Group for Blood and Marrow Transplantation (EBMT) (JACIE)

${ }^{1}$ Hematology, Department of Medicine, University Hospital Basel, Basel, Switzerland;

${ }^{2}$ Institute for Operations Research and Computational Finance, University of St Gallen, St Gallen, Switzerland and ${ }^{3}$ JACIE office, Hospital Clinic, Barcelona, Spain E-mail: hematology@uhbs.ch

\section{References}

1 Copelan EA. Hematopoietic stem-cell transplantation. N Engl J Med 2006; 354: 1813-1826.

2 Horowitz MM. Uses and growth of hematopoetic cell transplantation. In: Forman SJ, Blume KG, Thomas ED (eds). Hematopoietic Cell Transplantation, 3rd edn. Blackwell Scientific Publishers Inc.: London, New York, 2003, pp 9-15.

3 Ljungman P, Urbano-Ispizua A, Cavazzana-Calvo M, Demirer T, Dini $\mathrm{G}$, Einsele $\mathrm{H}$ et al. Allogeneic and autologous transplantation for haematological diseases, solid tumours and immune disorders: definitions and current practice in Europe. Bone Marrow Transplant 2006; 37: 439-449.

4 Thomas ED, Storb R, Clift RA, Fefer A, Johnson L, Neiman P et al. Bone-marrow transplantation (second of two parts). N Engl J Med 1975; 292: 895-902.

5 Gajewski JL, Foote M, Tietjen J, Melson B, Simmons A, Champlin RE. Blood and marrow transplantation compensation: perspective in payer and provider relations. Biol Blood Marrow Transplant 2004; 10: 427-432.

6 Warkentin PI. Hematopoietic stem and progenitor cell transplants: regulation and accreditation. Pediatr Transplant 2003; 7: 101-108. 
7 Barr RD. The importance of lowering the costs of stem cell transplantation in developing countries. Int J Hematol 2002; 76: 365-367.

8 Gratwohl A, Passweg J, Baldomero H, Horisberger B, UrbanoIspizua A, for the Accreditation Committee of the European Group for Blood and Marrow Transplantation (EBMT). Economics, health care systems and utilisation of Hematopoietic stem cell transplants in Europe. Br J Haematol 2002; 117: 451-468.

9 Gratwohl A, Baldomero H, Passweg J, Frassoni F, Niederwieser D, Schmitz N, et al., Accreditation Committee of the European Group for Blood and Marrow Transplantation (EBMT); working Parties Acute (ALWP) and Chronic Leukemias CLWP; Lymphoma Working Party. Hematopoietic stem cell transplantation for haematological malignancies in Europe. Leukemia 2002; 17: 941-959.

10 Druker BJ, Talpaz M, Resta DJ, Peng B, Buchdunger E, Ford JM et al. Efficacy and safety of a specific inhibitor of the BCR-ABL tyrosine kinase in chronic myeloid leukemia. N Engl J Med 2001; 344: 1031-1037.

11 O'Brien SG, Guilhot F, Larson RA, Gathmann I, Baccarani M, Cervantes $\mathrm{F}$ et al. IRIS investigators imatinib compared with interferon and low-dose cytarabine for newly diagnosed chronic phase chronic myeloid leukemia. N Engl J Med 2003; 348: 9941004.

12 Gratwohl A, Baldomero H, Frauendorfer K, Urbano-Ispizua A. Activity survey 2004 and changes in disease indication over the last 15 years. BMT 2006; 37: 1069-1085.

13 Gratwohl A, Baldomero H, Labar B, Apperley J, Urbano-Ispizua A, Accreditation Committee of the European Group for Blood and Marrow Transplantation (EBMT). Evoluation of hematopoietic stem cell transplantation in Eastern and Western Europe from 1990 to 2003 A report from the EBMT activity survey. Croat Med J 2004; 45: 689-6994.

14 Gratwohl A. Bone marrow transplantation activity in Europe 1990. Report from the European Group for Bone Marrow Transplantation (EBMT). Bone Marrow Transplant 1991; 8: 197-201.

15 Silver RT, Woolf SH, Hehlmann R, Appelbaum FR, Anderson J, Bennett $C$ et al. An evidence-based analysis of the effect of busulfan, hydroxyurea, interferon, and allogeneic bone marrow transplantation in treating the chronic phase of chronic myeloid leukemia: developed for the American Society of Hematology. Blood 1999; 94: 1517-1536.

16 Sawyers CL. Chronic myeloid leukemia. N Engl J Med 1999; 340: 1330-1340.

17 Rosti G, Baccarani M. Does early stem-cell transplantation have a role in chronic myeloid leukaemia? Against the proposal. Lancet Oncol 2005; 6: 722-723.
18 Gratwohl A. Does early stem-cell transplantation have a role in chronicd myeloid leukaemia? For the proposal. Lancet Oncol 2005; 6: 721-722.

19 Baccarani M, Saglio G, Goldman J, Hochhaus A, Simonsson B, Appelbaum $\mathrm{F}$ et al. Evolving concepts in the management of chronic myeloid leukemia. Recommendations from an expert panel on behalf of the European LeukemiaNet. Blood, (E-pub ahead of print 2006).

20 Ruiz-Arguelles GJ, Gomez-Almaguer D, Morales Torquero A, Gutierrez Aguirre $\mathrm{CH}$, Vela-Ojedo J, Garcia-Ruiz-Esparza MA et al. The early referral for reduced intensity stem cell transplantation in patients with ph+ chronic myelogenous leukemia in chronic phase in the imatinib era: results of the Latin American Cooperative Oncohematology Group (LACOHG) prospective multicenter study. Bone Marrow Transplant 2005; 36: 1043-1047.

21 Groot MT, van Agthoven M, Lowenberg B, Willemze R, Uyl-deGroot CA. The role of cost analysis in the evaluation of the development of medical technology. The case of allogeneic stemcell transplantation. Ned Tijdschr Geneeskd 2004; 148: 480-484.

22 Jacobs $\mathrm{P}$, Hailey D, Turner R, MacLean N. Allogeneic stem cell transplantation. An economic comparison of bone marrow, peripheral blood and cord blood technologies. Int J Technol Assess Health Care 2000; 16: 874-884.

23 Skrepnek GH, Ballard EE. Cost-efficacy of imatinib versus allogeneic bone marrow transplantation with a matched unrelated donor in the treatment of chronic myelogenous leukemia: a decision-analytic approach. Pharmacotherapy 2005; 25: 325-334.

24 Dalziel K, Round A, Stein K, Garside R, Price A. Effectiveness and cost-effectiveness of imatinib for first-line treatment of chronic myeloid leukaemia in chronic phase: a systematic review and economic analysis. Health Technol Assess 2004; 8: 1-120.

25 Gratwohl A, Brand R, Apperley J, Crawley C, Ruutu T, Corradini P et al. Chronic Leukemia Working Party of the European Group for Blood and Marrow Transplantation (EBMT). Haematologica 2006; 91: 513-521.

26 Woolhandler S, Himmelstein DU, Labar B, Lang S. Transplanted technology: Third World options and First World science. N Engl J Med 1987; 317: 504-506.

27 De Keersmacker K, Cools J. Chronic myeloproliferative disorders: a tyrosine kinase tale. Leukemia 2006; 20: 200-205.

28 Kantarjian H, Giles F, Wunderle L, Bhalla K, O'Brien S, Wassmann $\mathrm{B}$ et al. Nilotinib in imatinib-resistan $\mathrm{CML}$ and Philadelphia chromosome positive ALL. N Engl J Med 2006; 354: 2542-2551.

29 Talpaz M, Shah NP, Kantarjian H, Donato N, Nicoll J, Paquette R et al. Dasatinib in imatinib resistant Philadelphia chromosome positive leukemias. N Engl J Med 2006; 354: 2531-2541.

Supplementary Information accompanies the paper on the Leukemia website (http://www.nature.com/leu) 